\title{
Mechanisms of 4-quinolone resistance in quinolone- resistant and methicillin-resistant Staphylococcus aureus isolates from Japan and China
}

\author{
M. TANAKA, Y. X. ZHANG*, H. ISHIDA, T. AKASAKA, K. SATO and I. HAYAKAWA
}

Exploratory Research Laboratories 1, Daiichi Pharmaceutical Co. Ltd, 16-13 Kitakasai 1-chome, Edogawa-ku, Tokyo 134, Japan and "Hua Shan Hospital, Shanghai Medical University, Shanghai, Peoples Republic of China

\begin{abstract}
Summary. Ninety-two and 33 methicillin-resistant Staphylococcus aureus (MRSA) strains were isolated in Japan and China respectively. They were categorised as ofloxacin-susceptible $(\mathrm{MIC}<12.5 \mathrm{mg} / \mathrm{L}$ ), moderately (MIC $12.5-25 \mathrm{mg} / \mathrm{L}$ ) or highly (MIC $\geqslant 50 \mathrm{mg} / \mathrm{L}$ ) ofloxacinresistant. 4-Quinolone concentrations required to inhibit purified DNA gyrase from the moderately and highly quinolone-resistant MRSA were at least 20 times higher than those required to inhibit the equivalent enzyme from quinolone-susceptible strains. Reconstitution assays demonstrated that the 4-quinolone-resistant MRSA had a mutation in subunit $\mathrm{A}$ of DNA gyrase. A portion of the $g y r A$ gene from amino acids codons $40-115$ was sequenced. Four moderately resistant and seven highly resistant MRSA contained a Ser $\rightarrow$ Leu substitution at amino acid 84; one moderately and one highly resistant MRSA and one moderately resistant methicillin-susceptible $S$. aureus (MSSA) strain contained a Glu $\rightarrow$ Lys substitution at amino acid 88 . Eight MRSA, including one quinolone-susceptible strain and one MSSA contained a silent mutation at amino acid 86 . Uptake of ofloxacin in moderately resistant strains was almost the same in the presence or absence of carbonyl cyanide $\mathrm{m}$ chlorophenylhydrazone (CCCP), whereas in highly resistant strains, uptake increased when CCCP was added. Restriction fragment length analysis of the nor $A$ gene with the restriction endonuclease $S f c$ I showed a mutation of nucleotide position 1085 in all MRSA strains tested except for one highly quinolone-resistant strain. Thus the mechanisms of 4-quinoloneresistance in these MRSA isolates involved alterations in both DNA gyrase and antimicrobial uptake and efflux.
\end{abstract}

\section{Introduction}

Methicillin-resistant Staphylococcusaureus(MRSA) infections pose serious therapeutic difficulties, since only a few effective therapeutic agents are available. Although recently synthesised fluorinated 4-quinolone antibacterial agents are active against these strains, the increase in the clinical use of 4-quinolones has led to the widespread emergence of 4-quinolone-resistant strains. ${ }^{1}$ Three possible mechanisms of resistance to 4quinolones have been described: (1) alteration of DNA gyrase (gyr $A)$, (2) existence of an efflux system (nor $A)$ and alterations in the $c f x$-of $x$ locus. Previous workers have purified DNA gyrases from 4-quinolone-resistant MRSA and reported both alterations of subunit A of the enzyme as well as the accumulation of 4-quinolones in MRSA. ${ }^{2,3}$ DNA gyrase is a tetrameric protein consisting of two A and B subunits encoded by the gyr $A$ and gyr $B$ genes, respectively. Several point mutations in gyr $A$ that confer high-level fluoroquinolone resistance have been described. ${ }^{4-7}$ The membrane-associated active efflux pump (nor $A$ ) has also been reported as a mechanism of resistance, ${ }^{8-10}$ and the $c f x$-of $x$ locus reported by Trucksis $e t$ al. ${ }^{11}$ conferred low-level resistance (4-8-fold increase in MIC) to 4-quinolones.

Clinical isolates of MRSA from Japan and China were examined for 4-quinolone susceptibility along with the inhibitory action of these drugs on the supercoiling activities of DNA gyrases from the isolates and their uptake of ofloxacin. Genetic studies were also performed to identify the mechanism(s) of resistance to quinolones. 


\section{Materials and methods}

\section{Bacterial strains}

Fluoroquinolone-susceptible and -resistant MRSA were from six hospitals in Japan (92 isolates) and from the Hua Shan Hospital, Shanghai, China (33 isolates) and were isolated during 1987-1990. A fluoroquinolone-resistant methicillin-susceptible $S$. aureus (MSSA) isolate from Japan and $S$. aureus FDA 209-P were also used as controls.

\section{Antimicrobial agents}

The 4-quinolones ofloxacin, levofloxacin, DU$6859 \mathrm{a},{ }^{12}$ DV-7751a, ${ }^{13}$ ciprofloxacin, sparfloxacin, tosufloxacin and norfloxacin as well as nalidixic acid were synthesised at Daiichi Pharmaceutical Co., Ltd. Methicillin, kanamycin, vancomycin, rifampicin and chloramphenicol were purchased from Sigma. Tetracycline and minocycline were obtained from Lederle Japan (Tokyo, Japan). Gentamicin and amikacin were obtained from Schering Plough (Osaka, Japan) and Banyu Pharmaceutical Co. (Tokyo, Japan), respectively.

\section{MIC determination}

MICs were determined by standard agar dilution methods $^{14}$ with Mueller-Hinton Agar (Difco). One loopful $(5 \mu \mathrm{l})$ of an inoculum from an overnight culture, corresponding to $c .10^{4} \mathrm{cfu} / \mathrm{spot}$, was inoculated on drug-containing agar plates and the plates were incubated for $18 \mathrm{~h}$ at $37^{\circ} \mathrm{C}$. The MIC was defined as the lowest drug concentration that prevented visible growth of bacteria.

\section{Inhibition of DNA gyrase}

DNA gyrases were purified from $S$. aureus FDA 209-P and quinolone-resistant strains and assayed for quinolone inhibition of DNA supercoiling activity as described previously. ${ }^{15}$ The enzyme activity introduced into each reaction mixture was 1 unit $^{15}$ and the purity of subunit A and B was almost $90 \%$ on SDS-PAGE.

\section{Nucleotide sequence analysis of the gyr A gene}

Polymerase chain reaction (PCR) amplification of part of the $g y r A$ gene from quinolone-resistant strains was performed by the method of Hori et al. ${ }^{16}$ PCRamplified DNA was sequenced by the cycle sequencing $\operatorname{method}^{17}$ with a commercially available kit (New England Biolabs Co.). Thirty-five cycles were performed for each reaction as follows: $1 \mathrm{~min}$ at $93^{\circ} \mathrm{C}$, $1 \mathrm{~min}$ at $94^{\circ} \mathrm{C}, 1 \mathrm{~min}$ at $66^{\circ} \mathrm{C}$, and $1.5 \mathrm{~min}$ at $74^{\circ} \mathrm{C}$. The partial nucleotide sequences corresponding to the nucleotide positions $120-345$ of the gyr $A$ genes of $S$. aureus FDA 209-P and the resistant strains were determined.

\section{Uptake of quinolones}

The uptake of ofloxacin by $S$. aureus cells was 
Table II. Comparison of MICs (mg/L) of 4-quinolones with their inhibitory effect against DNA gyrase

\begin{tabular}{|c|c|c|c|c|c|c|c|c|c|c|c|c|}
\hline \multirow{2}{*}{ Strain no. } & \multicolumn{2}{|c|}{ Ofloxacin } & \multicolumn{2}{|c|}{ Levofloxacin } & \multicolumn{2}{|c|}{ DU-6859a } & \multicolumn{2}{|c|}{ DV-7751a } & \multicolumn{2}{|c|}{ Ciprofloxacin } & \multicolumn{2}{|c|}{ Sparfloxacin } \\
\hline & MIC & IC50 & MIC & IC50 & MIC & IC50 & MIC & IC50 & MIC & IC50 & MIC & IC 50 \\
\hline FDA 209-P & $0 \cdot 39$ & 26 & $0 \cdot 2$ & 19 & 0.006 & $0 \cdot 65$ & 0.025 & 0.86 & $0 \cdot 1$ & 36 & 0.05 & 25 \\
\hline $87-53$ & $0 \cdot 39$ & 110 & $0 \cdot 2$ & 65 & 0.025 & $7 \cdot 3$ & 0.05 & - & $0 \cdot 39$ & 110 & 0.05 & 45 \\
\hline $89-33$ & $12 \cdot 5$ & $>1600$ & $6 \cdot 25$ & $>1600$ & 0.78 & 85 & $1 \cdot 56$ & - & 25 & $>800$ & $6 \cdot 25$ & 1500 \\
\hline $90-37$ & 50 & $>1600$ & $12 \cdot 5$ & 1350 & 0.78 & 13 & $1 \cdot 56$ & - & 50 & $>800$ & $6 \cdot 25$ & 1100 \\
\hline 891185 & 200 & $>1600$ & 100 & 1590 & $12 \cdot 5$ & 15 & $12 \cdot 5$ & 77 & $>800$ & $>800$ & $12 \cdot 5$ & 509 \\
\hline 900165 & 100 & $>1600$ & 50 & $>1600$ & $3 \cdot 13$ & 61 & $6 \cdot 25$ & 270 & 400 & $>800$ & $12 \cdot 5$ & 600 \\
\hline
\end{tabular}

IC50, dose required to give $50 \%$ inhibition of enzyme activity $(\mathrm{mg} / \mathrm{L})$.

monitored by a fluorometric method. ${ }^{18}$ Bacteria in the logarithmic phase were collected, washed and suspended in $50 \mathrm{~mm}$ sodium phosphate buffer $(\mathrm{pH} 7 \cdot 2)$ corresponding to $40 \mathrm{~g} / \mathrm{L}$. Bacterial suspensions were incubated with ofloxacin for $10 \mathrm{~min}$ at $37^{\circ} \mathrm{C}$ at a final concentration of $10 \mathrm{mg} / \mathrm{L}$ in the presence or absence of carbonyl cyanide m-chlorophenylhydrazone (CCCP, Sigma) $5 \mathrm{mg} / \mathrm{L}(=25 \mu \mathrm{M})$. The results indicate the amount of ofloxacin $/ \mathrm{mg}$ of cells in the presence and absence of CCCP and the ratio of the amount of ofloxacin with $\mathrm{CCCP}$ to that without CCCP.

\section{Restriction fragment length analysis of the nor A gene}

PCR amplification of part of the nor $A$ gene from 4quinolone-resistant strains was performed by the method of Kaatz et al. ${ }^{19}$ PCR-amplified DNA $(0.5 \mathrm{mg} / \mathrm{L})$ was digested with the restriction endonuclease $S f c I$ and subjected to agarose gel electrophoresis. $S f c$ I digestion of the product which has cytosine at nucleotide position 1085 results in restriction fragments of 408 and $323 \mathrm{bp}$, whereas a substitution of adenine at this position eliminates the restriction site and leaves the 731-bp PCR product intact.

\section{Results}

\section{Susceptibility testing}

Table I shows the MICs of antibacterial agents against $S$. aureus FDA 209-P (standard strain), six MRSA (one 4-quinolone-susceptible and five -resist-

Table III. Inhibitory effects of 4-quinolones against reconstituted DNA gyrases

\begin{tabular}{lrrrr}
\hline & \multicolumn{4}{c}{ IC50 (mg/L) } \\
\cline { 2 - 5 } 4-quinolone & As-Bs & Ar-Bs & As-Br & Ar-Br \\
\hline OFLX $^{*}$ & 110 & $>1600$ & 32 & $>1600$ \\
CPFX $^{*}$ & 110 & $>800$ & 72 & $>800$ \\
OFLX & 26 & $>1600$ & 38 & $>1600$ \\
CPFX & 36 & $>800$ & 50 & $>800$
\end{tabular}

A, subunit A; B, subunit B; s, fluoroquinolone-susceptible MRSA (S. aureus $87-53)^{*}$ or $S$. aureus FDA 209-P $\dagger$; r, fluoroquinoloneresistant MRSA ( $S$. aureus $89-33^{*}$ or $S$. aureus $891185 \dagger$ ). OFLX, ofloxacin; CPFX, ciprofloxacin. ant strains) isolates from China, and eight 4quinolone-resistant strains (one MSSA and seven MRSA) isolated in Japan. Quinolone-resistant strains that showed higher MICs of ofloxacin among strains from each country were selected. Generally, the MICs of 4-quinolones against the Chinese $S$. aureus strains were lower than those of the Japanese strains. In contrast, 4-quinolone-resistant MRSA strains from China were resistant to aminoglycosides, tetracycline, minocycline, rifampicin and chloramphenicol. The MIC values in the resistant strains were increased for ofloxacin, levofloxacin and DV-7751a (32-512-fold) DU-6859a (64-2048-fold), sparfloxacin (32-256-fold), ciprofloxacin (128->8192-fold), tosufloxacin (128$>$ 4096-fold), norfloxacin (256-> 1024-fold) and nalidixic acid (4->16-fold) compared with the sensitive control strain $S$. aureus FDA 209-P.

\section{Inhibitory effect on DNA gyrases}

The inhibitory effects of 4-quinolones against the supercoiling activities of DNA gyrases are shown in table II. The $50 \%$ inhibitory concentrations (IC50s) of levofloxacin against purified DNA gyrases from quinolone-resistant MRSA were at least 20-fold higher than those against DNA gyrases from quinolonesusceptible MRSA 87-53 and S. aureus FDA 209-P. IC50s of sparfloxacin against $S$. aureus strains 89-33 and 90-37 were 2-3-fold higher than those against $S$. aureus strains 891185 and 900165 although the MIC values were in the reverse order. This tendency was also observed for levofloxacin. The difference in MICs against strains moderately and highly resistant to quinolones was not reflected in the inhibition of DNA gyrases. Although the MIC values of ofloxacin were the same in two quinolone-susceptible strains, the DNA gyrase from strain 87-53 had a four-fold increase in IC50 for ofloxacin than the enzyme from FDA 209$P$. This might be caused by differences in the uptake of quinolones. Reconstitution assay of subunits A and B from quinolone-resistant and -susceptible $S$. aureus strains showed that quinolone-resistant MRSA had a mutation in subunit A of DNA gyrase (table III).

\section{Nucleotide sequence analysis of the gyr $A$ gene}

The partial nucleotide sequences corresponding to the nucleotide positions $120-345$ of the gyr $A$ genes of 
Table IV. Mutations in gyrA in S. aureus

\begin{tabular}{|c|c|c|c|c|}
\hline Strain no. & $\begin{array}{c}\text { MIC of ofloxacin } \\
(\mathrm{mg} / \mathrm{L})\end{array}$ & Codon & Nucleotide mutation & Amino acid change \\
\hline FDA 209-P & $0 \cdot 39$ & 一 & - & - \\
\hline $87-53$ & 0.39 & 86 & $\mathrm{ATT} \rightarrow \mathrm{ATC}$ & $\mathrm{Ile} \rightarrow \mathrm{Ile}$ \\
\hline $87-20$ & $12 \cdot 5$ & 84,86 & $\mathrm{TCA} \rightarrow \mathrm{TTA}, \mathrm{ATT} \rightarrow \mathrm{ATC}$ & Ser $\rightarrow$ Leu, Ile $\rightarrow$ Ile \\
\hline $87-21$ & 25 & 88,86 & $\mathrm{GAA} \rightarrow \mathrm{AAA}, \mathrm{ATT} \rightarrow \mathrm{ATC}$ & Glu $\rightarrow$ Lys, Ile $\rightarrow$ Ile \\
\hline $89-33$ & $12 \cdot 5$ & 84,86 & $\mathrm{TCA} \rightarrow \mathrm{TTA}, \mathrm{ATT} \rightarrow \mathrm{ATC}$ & $\mathrm{Ser} \rightarrow \mathrm{Leu}, \mathrm{Ile} \rightarrow \mathrm{Ile}$ \\
\hline $89-36$ & $12 \cdot 5$ & 84,86 & $\mathrm{TCA} \rightarrow \mathrm{TTA}, \mathrm{ATT} \rightarrow \mathrm{ATC}$ & $\mathrm{Ser} \rightarrow \mathrm{Leu}, \mathrm{Ile} \rightarrow \mathrm{Ile}$ \\
\hline $89-43$ & $12 \cdot 5$ & 84,86 & $\mathrm{TCA} \rightarrow$ TTA, ATT $\rightarrow$ ATC & $\mathrm{Ser} \rightarrow \mathrm{Leu}, \mathrm{Ile} \rightarrow \mathrm{Ile}$ \\
\hline $90-37$ & 50 & 84,86 & $\mathrm{TCA} \rightarrow \mathrm{TTA}, \mathrm{ATT} \rightarrow \mathrm{ATC}$ & $\mathrm{Ser} \rightarrow$ Leu, Ile $\rightarrow$ Ile \\
\hline 890405 & 25 & 88,86 & $\mathrm{GAA} \rightarrow \mathrm{AAA}, \mathrm{ATT} \rightarrow \mathrm{ATC}$ & Glu $\rightarrow$ Lys, Ile $\rightarrow$ Ile \\
\hline 890664 & 100 & 84 & $\mathrm{TCA} \rightarrow$ TTA & Ser $\rightarrow$ Leu \\
\hline 890669 & 100 & 84 & $\mathrm{TCA} \rightarrow \mathrm{TTA}$ & Ser $\rightarrow$ Leu \\
\hline 890670 & 100 & 84 & $\mathrm{TCA} \rightarrow \mathrm{TTA}$ & Ser $\rightarrow$ Leu \\
\hline 890952 & 100 & 84 & $\mathrm{TCA} \rightarrow \mathrm{TTA}$ & Ser $\rightarrow$ Leu \\
\hline 890958 & 50 & 88,86 & $\mathrm{GAA} \rightarrow \mathrm{AAA}, \mathrm{ATT} \rightarrow \mathrm{ATC}$ & Glu $\rightarrow$ Lys, Ile $\rightarrow$ Ile \\
\hline 891185 & 200 & 84 & $\mathrm{TCA} \rightarrow \mathrm{TTA}$ & Ser $\rightarrow$ Leu \\
\hline 900165 & 100 & 84 & $\mathrm{TCA} \rightarrow \mathrm{TTA}$ & Ser $\rightarrow$ Leu \\
\hline
\end{tabular}

Table V. Uptake of ofloxacin and RFLP analysis by $S f c \mathrm{I}$ of nor $A$

\begin{tabular}{|c|c|c|c|c|}
\hline Strain no. & $\begin{array}{c}\text { Amount of } \\
\text { ofloxacin } \\
\text { without } \mathrm{CCCP}^{*}\end{array}$ & $\begin{array}{c}\text { Amount of } \\
\text { ofloxacin } \\
\text { with } \mathrm{CCCP}^{*}\end{array}$ & $\begin{array}{l}\text { Ratio of } \\
\text { uptake } \\
\text { ofloxacin } †\end{array}$ & $\begin{array}{c}\text { Retention of } \\
\text { the } S f c I \\
\text { restriction site } \neq\end{array}$ \\
\hline FDA 209-P & $60 \cdot 62$ & $42 \cdot 27$ & 0.7 & - \\
\hline $87-53$ & $139 \cdot 26$ & 135.02 & 0.97 & + \\
\hline $87-20$ & $162 \cdot 35$ & 177.07 & 1.09 & + \\
\hline $87-21$ & $145 \cdot 1$ & 148.03 & 1.02 & + \\
\hline $89-33$ & $107 \cdot 88$ & $111 \cdot 1$ & 1.03 & + \\
\hline $89-36$ & $155 \cdot 35$ & 189.6 & $1 \cdot 22$ & + \\
\hline $89-43$ & 147.66 & $188 \cdot 67$ & $1 \cdot 27$ & + \\
\hline $90-37$ & 92.93 & 169.7 & 1.83 & + \\
\hline 890405 & $77 \cdot 23$ & $107 \cdot 28$ & 1.39 & - \\
\hline 890664 & $21 \cdot 45$ & $121 \cdot 94$ & 5.68 & + \\
\hline 890669 & $34 \cdot 86$ & $168 \cdot 16$ & $4 \cdot 82$ & + \\
\hline 890670 & $90 \cdot 6$ & 197.06 & $2 \cdot 18$ & + \\
\hline 890952 & $59 \cdot 6$ & $193 \cdot 73$ & $3 \cdot 25$ & + \\
\hline 890958 & $103 \cdot 17$ & $189 \cdot 58$ & 1.84 & - \\
\hline 891185 & 94.88 & $158 \cdot 5$ & 1.67 & + \\
\hline 900165 & $117 \cdot 31$ & $182 \cdot 24$ & 1.55 & + \\
\hline
\end{tabular}

\section{*ng/mg.}

$\uparrow$ The ratio of the amount of ofloxacin in cells with CCCP/that without CCCP after incubation for $10 \mathrm{~min}$.

$\$ A^{\prime}+$ ' indicates that the DNA fragment has the mutation of cytosine at nucleotide position 1085 , rather than adenine, and is thus susceptible to restriction digestion.

13 MRSA strains (five moderately resistant and eight highly resistant to 4-quinolones), one 4-quinolonesusceptible MRSA, one 4-quinolone-resistant MSSA and strain FDA 209-P were determined (table IV). Eleven of these 13 strains (four moderately resistant and seven highly resistant to quinolones) contained a Ser $\rightarrow$ Leu substitution caused by an alteration at codon 84, and two strains moderately resistant and one highly resistant to 4-quinolones contained a Glu $\rightarrow$ Lys substitution caused by an alteration at codon 88. Eight MRSA, including one 4-quinolonesusceptible strain and one MSSA, contained a silent mutation at codon 86 .

\section{Uptake of ofloxacin by MRSA}

Uptake of ofloxacin by $S$. aureus cells is shown in table $V$. The amount of ofloxacin in 4-quinolonesusceptible strains remained unchanged when CCCP was added. The ratio of the amount of ofloxacin in MRSA moderately resistant to 4-quinolones in the presence and absence of CCCP ranged from 1.02 to 1.39; these values are less than double the ratio in $S$. aureus FDA 209-P. In contrast, this ratio in strains highly resistant to 4-quinolones ranged from 1.55 to $5 \cdot 68$.

\section{Restriction fragment length analysis of the nor A gene}

$S f c I$-digestion of the PCR product with cytosine instead of adenine at nucleotide position 1085 results in restriction fragments of 408 and $323 \mathrm{bp}$. Thirteen of 14 MRSA strains showed a mutation in nor $A$ at codon 362; strain FDA 209-P, one 4-quinolone-resistant MSSA (strain 890405) and one 4-quinolone-resistant MRSA (strain 890958) had no mutation in nor $A$ at codon 362 (table V). The latter two strains were less resistant to ofloxacin than the other six Japanese 
strains (table I). This result showed no correlation with the uptake of ofloxacin.

\section{Discussion}

The pattern of susceptibility of MRSA strains to antimicrobial agents varied between the two countries. Japanese strains were less resistant to antibiotics than the Shanghai strains. In Japan, the use of rifampicin is generally limited only to the treatment of tuberculosis, and the use of tetracyclines and chloramphenicol is now insignificant. Vancomycin had a good antibacterial activity against all $S$. aureus strains and tetracyclines and gentamicin are expected to have clinical efficacy against MRSA infections in Japan However, the level of resistance to quinolones was lower in China than Japan, where 4-quinolones have been used for 10 years. In China, although other antibiotics have long been widely used, 4-quinolones were only introduced in 1987 although their usage has recently increased (personal communication, Dr Wang Fu, Shanghai Medical University).

In the present study, the mechanism(s) of resistance to 4-quinolones among MRSA strains were investigated. DNA gyrase was purified and the MICs of 4quinolones for various MRSA strains were determined. Although MIC values against MRSA were different, IC50 values were similar, with the predominant mutation occurring in the A subunit of DNA gyrase. Nucleotide sequence analysis of the gyr $A$ gene showed that 11 strains (four moderately resistant and seven highly resistant to 4-quinolones) contained a Ser $\rightarrow$ Leu substitution resulting from a mutation in codon 84 , and that two strains moderately resistant

\section{References}

1. Shalit I, Berger SA, Gorea A, Frimerman H. Widespread quinolone resistance among mechicillin-resistant Staphylococcus aureus isolates in a general hospital. Antimicrob Agents Chemother 1989; 33: 593-594.

2. Nakanishi N, Yoshida S, Wakebe H, Inoue M, Yamaguchi T, Mitsuhashi S. Mechanisms of clinical resistance to fluoroquinolones in Staphylococcus aureus. Antimicrob Agents Chemother 1991; 35: 2562-2567.

3. Okuda J, Okamoto S, Takahata $\mathbf{M}$, Nishino $T$. Inhibitory effects of ciprofloxacin and sparfloxacin on DNA gyrase purified from fluoroquinolone-resistant strains of methicillin-resistant Staphylococcus aureus. Antimicrob Agents Chemother 1991; 35: 2288-2293.

4. Sreedharan S, Oram M, Jensen B. Peterson LR, Fisher LM. DNA gyrase gyrA mutations in ciprofloxacin-resistant strains of Staphylococcus aureus: close similarity with quinolone resistance mutations in Escherichia coli. $J$ Bacteriol 1990; 172: 7260-7262.

5. Sreedharan S, Peterson LR, Fisher LM. Ciprofloxacin resistance in coagulase-positive and -negative staphylococci: role of mutations at serine 84 in the DNA gyrase A protein of Staphylococcus aureus and Staphylococcus epidermidis. Antimicrob Agents Chemother 1991; 35: 2151-2154.

6. Fasching CE, Tenover FC, Slama TG et al. Gyr A mutations in ciprofloxacin-resistant, methicillin-resistant Staphylococcus aureus from Indiana, Minnesota, and Tennessee. J Infect Dis 1991; 164: 976-979.

7. Goswitz JJ, Willard KE, Fasching CE, Peterson LR. Detection of gyrA gene mutations associated with ciprofloxacin resistance in methicillin-resistant Staphylococcus aureus: analysis by polymerase chain reaction and automated and one highly resistant to 4-quinolones contained a Glu $\rightarrow$ Lys substitution resulting from a mutation in codon 88 . Mutations at codons 84,85 and 88 have been reported to confer quinolone resistance in $S$. aureus $;^{4-7}$ however, no mutation at codon 85 was found in this study. Moreover, a silent mutation at codon 86 was found in eight MRSA, including one 4-quinolone-susceptible strain, and in one MSSA. Tokue et al. reported this mutation in one fluoroquinolone-susceptible strain isolated in the Tohoku region of Japan. ${ }^{20}$ All the Chinese, but only two of the Japanese strains contained this point mutation.

The nor $A$ gene, which is responsible for quinolone resistance related to the efflux system, has been cloned from the chromosomal DNA of $S$. aureus. ${ }^{8-10}$ To clarify the difference in susceptibility to quinolones, the uptake of ofloxacin into MRSA was also examined. In strains with ofloxacin MIC values of 12.5 and $25 \mathrm{mg} / \mathrm{L}$, the ratio of the amount of uptake without CCCP compared to that with CCCP was within twofold that of $S$. aureus FDA 209-P, whereas in those with $\mathrm{MICs}>50 \mathrm{mg} / \mathrm{L}$, this ratio ranged widely. From these results, we speculate that MRSA acquire resistance to 4-quinolones by the alteration of DNA gyrase and by the development of an active efflux system. Restriction fragment length analysis of the nor $A$ gene with the restriction endonuclease $S f c I$ showed a mutation in nor $A$ at codon 362. This result did not correspond to the uptake of ofloxacin, and showed no regional differences. Kaatz et al. reported that an increase in transcription of the nor $A$ gene was a cause of 4-quinolone-resistance. ${ }^{19}$

PCR.

We thank Ms Yuki Kaibori for preparation of the primers for direct DNA sequencing. Antimicrob Agents Chemother 1992; 36: 1166-1169.

8. Ubukata K, Itoh-Yamashita N, Konno M. Cloning and expression of the nor $A$ gene for fluoroquinolone resistance in Staphylococcus aureus. Antimicrob Agents Chemother $1989 ; 33$ : 1535-1539.

9. Yoshida H, Bogaki M, Nakamura S, Ubukata K, Konno M. Nucleotide sequence and characterization of the Staphylococcus aureus nor $A$ gene, which confers resistance to quinolones. $J$ Bacteriol 1990; 172: 6942-6949.

10. Yoshida S. Kojima T, Inoue M, Mitsuhashi S. Uptake of sparfloxacin and norfloxacin by clinical isolates of Staphylococcus aureus. Antimicrob Agents Chemother 1991; 35: 368-370.

11. Trucksis M, Wolfson JS, Hooper DC. A novel locus conferring fluoroquinolone resistance in Staphylococcus aureus. $J$ Bacteriol 1991; 173: 5854-5860.

12. Sato K, Hoshino K, Tanaka M, Hayakawa I, Osada Y. Antimicrobial activity of DU-6859, a new potent fluoroquinolone, against clinical isolates. Antimicrob Agents Chemother 1992; 36: 1491-1498.

13. Tanaka M, Hoshino K, Ishida H, Sato K, Hayakawa I, Osada Y. Antimicrobial activity of DV-7751a, a new fluoroquinolone. Antimicrob Agents Chemother 1993; 37: 2112-2118.

14. National Committee for Clinical Laboratory Standards. Methods for dilution antimicrobial susceptibility tests for bacteria that grow aerobically. Approved standard M7-A2 (2nd). National Committee for Clinical Laboratory Standards, Villa Nova, PA, USA. 1990.

15. Tanaka M, Sato K, Kimura Y, Hayakawa I, Osada Y, Nishino T. Inhibition by quinolones of DNA gyrase from Staphy- 
lococcus aureus. Antimicrob Agents Chemother 1991; 35 : 1489-1491.

16. Hori S, Ohshita Y, Utsui Y, Hiramatsu K. Sequential acquisition of norfloxacin and ofloxacin resistance by methicillin-resistant and -susceptible Staphylococcus aureus. Antimicrob Agents Chemother 1993; 37: 2278-2284.

17. Murray V. Improved double-stranded DNA sequencing using the linear polymerase chain reaction. Nucleic Acids Res $1989 ; 17: 8889$.

18. Chapman JS, Georgopapadakou NH. Fluorometric assay for fleroxacin uptake by bacterial cells. Antimicrob Agents Chemother 1989; 33: 27-29.

19. Kaatz GW, Seo SM, Ruble CA. Efflux-mediated fluoroquinolone resistance in Staphylococcus aureus. Antimicrob Agents Chemother 1993; 37: 1086-1094.

20. Tokue Y, Sugano K, Saito D et al. Detection of novel mutations in the gyrA gene of Staphylococcus aureus by nonradioisotopic single-strand conformation polymorphism analysis and direct DNA sequencing. Antimicrob Agents Chemother 1994; 38: 428-431. 